\title{
Growth-Promoting Effects of Press Water from the Mechanical Drying of Douglas-Fir Wood Chips on Lignocellulolytic Fungi
}

\section{Manfred J. Reppke}

Technical University of Munich

\section{Rebecca Gerstner}

Technical University of Munich

Elisabeth Windeisen-Holzhauser

Technical University of Munich

\section{Klaus Richter}

Technical University of Munich

\section{J. Philipp Benz ( $\sim$ benz@hfm.tum.de )}

Technical University of Munich

\section{Research Article}

Keywords: Wood press water, media supplements, biorefinery, lignocellulolytic fungi, Trichoderma reesei, cellulase, bio-clarification

Posted Date: January 25th, 2022

DOI: https://doi.org/10.21203/rs.3.rs-1279036/v1

License: (c) (1) This work is licensed under a Creative Commons Attribution 4.0 International License. Read Full License 


\section{Abstract}

\section{Background:}

The mechanical drying of wood chips is an innovative method that improves the heating value of sawmill by-products in an energy-efficient continuous process. The liquid that comes out of the wood chips as press water (PW), however, contains a variety of undissolved as well as dissolved organic substances. The disposal of the PW as wastewater would generate additional costs due to its high organic load, offsetting the benefits in energy costs associated with the enhanced heating value of the wood chips. Our research explored if the organic load in PW could be utilized to boost the growth of cellulolytic filamentous fungi. Hence, using the industrially relevant Ascomycete Trichoderma reesei RUT-C30 as well as several Basidiomycete wood-rotting fungi, we examined the potential of press water obtained from Douglas-fir wood chips to be used in growth and enzyme production media.

\section{Results:}

The addition of PW supernatant to liquid cultures of T. reesei RUT-C30 resulted in a significant enhancement of the endoglucanase and endoxylanase activities with a substantially shortened lagphase. Supplementation with PW allowed to replace several mineral ions $\left(\mathrm{Fe}^{2+}, \mathrm{Mn}^{2+}, \mathrm{Zn}^{2+}, \mathrm{Ca}^{2+}, \mathrm{Mg}^{2+}\right.$, $\mathrm{K}^{+}$) from the liquid media without negative effects on the enzymatic activities. Concentrations of PW above $50 \%$ showed no adverse effects regarding the achievable endoglucanase activity but affected the endoxylanase activity to some extent. Exploring the growth-enhancing potential of several individual PW components after chemical analysis revealed that the observed lag-phase reduction of T. reesei RUT-C30 was not caused by the dissolved sugars and ions, nor the wood solids in the PW, suggesting that other, so far non-identified, compounds are responsible. However, also the growth rate of several basidiomycetes was significantly enhanced by the supplementation of PW to the agar medium. Moreover, their cultivation in liquid cultures reduced the turbidity of the PW substantially.

\section{Conclusions:}

PW was identified as a suitable media supplement for lignocellulolytic fungi, including the cellulase and xylanase producer $T$. reesei RUT-C30 and several wood-degrading basidiomycetes. The possibility to replace several minerals, trace elements and an equal volume of fresh water in liquid media with PW and the ability of fungal mycelia to filter out the suspended solids is a promising way to combine biological wastewater treatment with value-adding biotechnological applications.

\section{Introduction}

Sawmills generate large quantities of by-products, such as bark, sawdust, and wood chips. The average yield of sawn timber from round wood in sawmills has been reported to be around $60 \%$, which means around $40 \%$ of the round wood ends up as a by-product [1-3]. The total production of wood chips, particles and residues in Germany reached an estimated 10.97 million $\mathrm{m}^{3}$ in 2019 [4]. Wood chips are 
often sold to thermal power stations or to the pulp and paper industry. Nonetheless, a large portion of these by-products is generally used for internal energy production [2]. With average moisture contents of 40 to $50 \%$-wet basis $(\mathrm{wb})$ after production, microbial activity is facilitated during storage, which can increase the risk for spontaneous combustion due to heat accumulation inside the piles [5] as well as to considerable dry matter and energy loss [6-8]. Technical drying is therefore necessary to achieve suitable moisture contents that both prevent microbial activity and guarantee high fuel quality $[9,10]$.

Conventional drying methods based on the evaporation of moisture mostly use thermal energy from dedicated combustion of biogenic or fossil fuels $[11,12]$. Regardless of the type of thermal dryer, energy efficiency and drying rate are critical issues associated with thermal drying methods [13]. Mechanical dewatering, on the other hand, is a process that uses high pressure [14]. The increased pressure within the wood will force the free water in the cell lumen to find multiple ways out, e.g. through the pits or cracks in the cell walls $[15,16]$. The energy required in compression and thus for expulsion of the water is much lower than the energy required to vaporize the same water using thermal energy [17]. The combination of mechanical squeezing and thermal drying can therefore lead to substantial energy savings compared exclusively thermal drying $[18,19]$.

Large quantities of press water (PW) are released during the mechanical dewatering of wood chips. Ultimately, the generated volume of PW will depend on the quality and quantity of the wood chips being processed at sawmills. Since the PW originates from the free water in the lumen of the wood cells, it will contain chemical wood constituents, such as dissolved minerals, sugars, or other extractives. These substances could have negative effects for aquatic ecosystems if the disposal of press water is not performed adequately $[20,21]$. Among the PW of different wood species, e.g. Pine, Fir, Spruce, Poplar, and Beech, Douglas-fir showed the highest phenol index, chemical and biochemical oxygen demand [22]. Moreover the chemical oxygen demand (COD), which describes the amount of oxygen required to oxidize the organic material, of the tested PW was above $10,000 \mathrm{mg} \mathrm{L}^{-1}$ with an acidic $\mathrm{pH}$, and none of the tested PWs showed a $100 \%$ degradability of the water-soluble organic substances (Zahn-Wellens-Test) with Douglas-fir PW having the least degradability with only $83 \%$ [22]. Therefore, similar to the effluents of pulp and paper mills, PW must be treated before being released into water bodies or even before entering the local wastewater treatment plants $[23,24]$. Depending on the local regulations for wastewater disposal, the economic costs of PW treatment could offset the benefits associated with the reduced energy costs of mechanical drying compared to an exclusively thermal drying [18, 19]. Hence, alternative applications should be examined.

Instead of viewing it as a wastewater, the organically loaded PW could act as a low-cost substrate for enzyme production in fungal cultivations, thus becoming a by-product of the mechanical drying and not a waste. The ability to degrade lignocellulose is widespread in fungi of the Ascomycota and Basidiomycota phyla [25]. The ascomycete filamentous fungus Trichoderma reesei is a major producer of carbohydrate active enzymes (CAZymes), which are used for the conversion of plant biomass to sustainable fuels and chemicals [26-28]. The high cost of enzyme production as an important factor for the economic feasibility of biorefineries, especially for the production of biofuels, has driven the development of several 
hypercellulolytic mutant strains [29-31]. One of these strains, RUT-C30, has been extensively studied in academic research [32]. Additionally, wood-decaying basidiomycetes, which are typically classified as white rots or brown rots, have evolved alongside their plant hosts and developed distinct strategies for the degradation of lignin along cellulose and hemicelluloses [33-35]. White rots produce multiple lignindegrading peroxidases, which allow them to degrade lignin, aside from other cell wall components like cellulose and hemicelluloses [36,37]. On the other hand, brown rots leave lignin largely intact due to a lack of lignin-degrading peroxidases [36, 38]. These lignin-degrading enzymes make basidiomycetes interesting for industrial and biotechnological applications [39].

Generally, media for fungal enzyme production require high amounts of carbon and nitrogen sources. Aside from that, fungal media require considerable amounts of other macro nutrients, like sulfate, phosphate, $\mathrm{K}^{+}, \mathrm{Ca}^{2+}$ and $\mathrm{Mg}^{2+}$. Furthermore, several micro elements, like $\mathrm{Fe}^{2+}, \mathrm{Mn}^{2+}, \mathrm{Zn}^{2+}, \mathrm{Co}^{2+}$, are required. While necessary in much lower concentrations, these are nevertheless very important for the production of enzymes and other cofactors $[40,41]$.

The carbon source, which optimally serves both as an energy source and inducer molecule, accounts for a substantial portion of the cultivation costs. Therefore, the identification of abundant low cost residues, which display good rheological properties, are non-toxic, and induce cellulase production, have led to the utilization of various side products, like lactose and sugarcane bagasse [42, 43]. To this end, the PW could become an interesting side stream of the sawmill industry, which could have a huge potential to be used as media supplement in the production of cellulolytic enzymes.

For this study, we chose Pseudotsuga menziesii (Douglas-fir) as the PW source, since it displayed the highest organic load among other wood species [22]. Furthermore, Douglas-fir is the most widespread non-native tree species in Germany, covering $2 \%$ of the total forest area, with an expected increase in relevance in the coming years due to its desirable wood properties, small vulnerability to summer drought, and volume growth per hectare that exceeds that of native European tree species [44-46].

The aim of the present study was to analyze the potential of Douglas-fir-derived PW as a low-cost media supplement in the cultivation of wood degrading filamentous fungi. Since little is known about the PW composition, we initially investigated relevant physico-chemical characteristics of the PW, like dissolved ions, sugars, amount of solids and composition of the solids. We then tested the production of cellulases and xylanases with $T$. reesei RUT-C30 during growth on PW-supplemented media. Furthermore, the ability of several basidiomycetes to grow on PW-containing media and to clarify the aqueous medium containing suspended PW-solids was investigated (Fig. 1).

\section{Results}

\section{Chemical oxygen demand}


The chemical oxygen demand (COD) of PW was analyzed to evaluate its organic load and the overall environmental impact. The results show that pure PW has a rather high organic load with a maximum of $10,750 \mathrm{mg} \mathrm{L}^{-1}$. The removal of macro solids from the PW by centrifugation lowered the COD to $8,800 \mathrm{mg} \mathrm{L}^{-1}$. Ultimately, the high COD values of the PW are indicative for a high concentration of dissolved organic substances that are problematic in wastewater treatment but could be beneficial for fungal cultivations.

\section{Physico-chemical analysis}

The analyzed PW was a heterogeneous suspension containing solids of different sizes and shapes (Fig. 2a). Even after centrifugation the liquid fraction remained turbid and colored, suggesting a high quantity of dissolved substances and suspended particles (Fig. 2b). Furthermore, the rather low pH of 4.42 indicates the presence of acidic organic substances.

\section{Phenotype of T. reesei RUT-C30 on PW agar}

To characterize the growth phenotype of $T$. reesei RUT-C30 on different media including or excluding PW, agar plates were inoculated with the same concentration of conidia and cultivated under identical conditions. Three types of Mandels-Andreotti (MA) salt-based solid media were prepared: plain MA agar without any carbon source, MA agar with $0.2 \mathrm{~g} \mathrm{~L}^{-1}$ glucose, and MA agar with PW supernatant but without additional glucose. To observe the growth of $T$. reesei also on PW alone, one additional PW medium was prepared without MA salts as a control.

A clear growth difference was observed, particularly regarding the color of the conidia, which turned green on PW but stayed yellow on media without PW (Fig. 5). Moreover, T. reesei yielded a significantly higher spore number on the plates with PW. The addition of glucose to the MA agar only slightly increased sporulation, and PW medium without the addition of MA salts was not sufficient for optimal growth (Fig. $5)$.

\section{Liquid cultivation in PW supernatant with surplus of nutrients}

In the following, we cultivated T. reesei RUT-C30 in liquid cultures with different concentrations of PW supernatant (after centrifugation) to observe the effects on endoglucanase and endoxylanase production. Here, the liquid cultures were formulated with the complete MA medium and hence, the ion concentrations varied slightly, depending on the used PW volumes.

The enzymatic activities of the culture supernatants showed substantial enhancement in PW media compared to the control condition (Fig. 4a). Most noticeably, only the PW-supplemented cultures 
displayed enzymatic activities already at day 3 , whereas the control media with $0 \% \mathrm{PW}$ needed several days more to reach the same level of activity. The activities seen in the culture supernatants with PW continued to be significantly higher than the controls throughout the cultivations, except for the endoxylanase activity in $100 \%$ PW, which was noticeably lower than the other PW conditions. However, the gap between the activities measured in $0 \%$ PW and $25-75 \%$ PW decreased over the course of the cultivation period. For instance, the endoglucanase activities measured in the PW supernatants were on average 8.8-fold higher at day 5 and only 2.5 -fold higher at day 7 compared to the control without PW. Similarly, the endoxylanase activity measured between $25 \%$ and $75 \%$ PW displayed a 2.3-fold and 1.9fold increase relative to the control at day 5 and 7, respectively. No significant difference in enzymatic activities was observed among the cultures with different PW dilutions. These results demonstrate that PW addition can robustly enhance the production of cellulase and xylanase enzymes in T. reesei RUT-C30 over a broad concentration window.

\section{Liquid cultivation in PW with replacement of salts and C- source}

Since PW contains several nutrients in relevant quantities (mainly trace elements but also theoretically hydrolysable solids; Table 1, Fig. 2d), we wanted to test whether some of the components of the conventional fungal cultivation medium (MA) could be replaced by raw PW (with solids, not centrifuged). The minimal PW concentration at which the trace elements could be eliminated from the MA medium was $55 \%$ raw PW, as calculated based on the zinc concentration (Table 1). Since cobalt was not measured in the PW it had to be supplemented separately. However, at this dilution level, iron and manganese concentrations are higher than in the conventional MA medium. Particularly high concentrations of $\mathrm{Fe}^{3+}$ ions were reported to be inhibitory for the saccharification of cellulose in other fungi [47]. Therefore, to elucidate whether an overdose of trace elements would have negative effects, we prepared a control condition with 50x trace elements. Furthermore, the carbon source Avicel was replaced based on the theoretically hydrolysable solids in the PW (Table 2). The soluble monosaccharides were not considered in this case.

The distribution of the volume-weighed particle size of the PW supernatant was measured by laser diffraction. The particles in the PW supernatant (after centrifugation at 4,000 rcf for $15 \mathrm{~min}$ ) showed a monomodal distribution, with most of the particles displaying a diameter of $1 \mu \mathrm{m}$ and a maximum particle size of ca. $100 \mu \mathrm{m}$ (Fig. 2c). Further separation of these suspended particles would require centrifugation at higher speeds, longer settling times or extensive filtration. The PW was fractionated by means of centrifugation and membrane filtration into sedimented macro solids, filtered micro solids, and dissolved substances, which were quantified gravimetrically. The total concentration of solids and

dissolved substances in PW amounted to $10.38 \pm 0.07 \mathrm{~g} \mathrm{~L}^{-1}$ (Fig. 2d). Dissolved substances represented the largest fraction of the PW with $6.31 \pm 0.04 \mathrm{~g} \mathrm{~L}^{-1}$. The concentration of macro solids (at 
$3.40 \pm 0.30 \mathrm{~g} \mathrm{~L}^{-1}$ ) and micro solids (at $0.67 \pm 0.05 \mathrm{~g} \mathrm{~L}^{-1}$ ) together accounted for about $40 \%$ of the total dry mass.

An acid hydrolysis was performed to further investigate the composition of the macro solids in PW (Fig. 2e). Three fractions were obtained and quantified, namely hydrolysable polysaccharides (Hydrolysate), acid-insoluble residues (AIR), and acid-soluble aromatics (ASA). The hydrolysable polysaccharides in the solids of the PW accounted for $51.2 \%(\mathrm{w} / \mathrm{w})$. Assuming that these are predominantly cellulose and hemicelluloses, a maximum of $1.73 \mathrm{~g} \mathrm{~L}^{-1}$ of the PW solids could potentially serve as a carbon source and inducer to produce cellulolytic enzymes in fungal fermentations.

To better elucidate the composition of the acid-insoluble residues (making up $47.3 \%(\mathrm{w} / \mathrm{w})$ ), we performed a pyrolysis GC/MS to identify the major pyrolysis products. The largest peaks were distributed in three main groups, corresponding to phenols (2-methoxy-4-methylphenol, 1,2-dihydroxybenzene, 2methoxy-4-vinylphenol), fatty acids (oleic acid), and phytosterols (campesterol, stigmasta-3,5-diene) (Fig. 2f). The absence of levoglucosan was a good indication for the successful hydrolysis, since it is a pyrolysis product from carbohydrates. These results suggest that the polysaccharides in the PW solids were effectively hydrolyzed leaving only the phenol-rich polymers and some resin derivatives behind.

\section{Dissolved phenolic compounds}

To analyze the dissolved phenolic compounds we concentrated the PW using a solid phase extraction (SPE) on C18 silica and the methanol soluble fraction was analyzed using GC/MS. The chromatogram (Additional file: Fig. S6) showed the presence of some phenolic substances, like 3-(4-hydroxyphenyl)-1propanol, and sugar derivatives. However, the flavonoid taxifolin was found to be the most abundant compound in the PW at a concentration of $7.4 \%(w / w)$ in the extract.

\section{Dissolved ions}

The most abundant ions measured according to standard methods for the examination of water in the PW were potassium $\left(\mathrm{K}^{+} ; 130 \mathrm{mg} \mathrm{L}^{-1}\right)$, calcium $\left(\mathrm{Ca}^{2+} ; 49.2 \mathrm{mg} \mathrm{L}^{-1}\right)$, and $\mathrm{SO}_{4}{ }^{2-}\left(38 \mathrm{mg} \mathrm{L}^{-1}\right)$ (Table 1), followed by iron $\left(\mathrm{Fe}^{2+} ; 20.10 \mathrm{mg} \mathrm{L}^{-1}\right)$, magnesium $\left(\mathrm{Mg}^{2+} ; 14.60 \mathrm{mg} \mathrm{L}^{-1}\right)$, manganese $\left(\mathrm{Mn}^{2+} ; 4.83 \mathrm{mg} \mathrm{L}^{-1}\right)$, sodium $\left(\mathrm{Na}^{+} ; 4.28 \mathrm{mg} \mathrm{L}^{-1}\right)$, and zinc $\left(\mathrm{Zn}^{2+} ; 0.61 \mathrm{mg} \mathrm{L}^{-1}\right)$. As expectable from wood, $\mathrm{PW}$ was found to be a poor source of nitrogen with nitrate concentrations below detection range and only $1.43 \mathrm{mg} \mathrm{L}^{-1}$ of ammonium.

\section{Sugar analysis}

The most abundant monosaccharides in the PW measured using HPAEC-PAD were fructose and glucose with $0.60 \mathrm{~g} \mathrm{~L}^{-1}$ and $0.24 \mathrm{~g} \mathrm{~L}^{-1}$, respectively, followed by galactose $\left(0.09 \mathrm{~g} \mathrm{~L}^{-1}\right)$ and arabinose $\left(0.03 \mathrm{~g} \mathrm{~L}^{-1}\right)$. 
Xylose (13.81 $\left.\mathrm{mg} \mathrm{L}^{-1}\right)$ and mannose $\left(2.77 \mathrm{mg} \mathrm{L}^{-1}\right)$ were the least abundant detectable sugars. The disaccharide concentrations of cellobiose and sucrose were $2.77 \mathrm{mg} \mathrm{L}^{-1}$ and $1.9 \mathrm{mg} \mathrm{L}^{-1}$, respectively. The combined concentration of mono- and disaccharides in the PW amounted to $0.99 \mathrm{~g} \mathrm{~L}^{-1}$ (see Additional file: Fig. S1).

Comparable to the results seen on PW supernatant, the effect of the raw PW was most noticeable at day 3 , where endoglucanase and endoxylanase activities of the cultures were significantly higher than the MA control (Fig. 4b). The highest endoglucanase activities were observed after 7 days of cultivation in $55 \%$ $\left(11.5 \pm 1.2 \mathrm{U} \mathrm{mL}^{-1}\right)$ and $25 \% \mathrm{PW}\left(11.3 \pm 0.5 \mathrm{U} \mathrm{mL}^{-1}\right)$. The endoxylanase activities showed a clear advantage at $25 \%$ PW, which yielded significantly higher activities than the other PW conditions, reaching a maximum activity of $20.3 \mathrm{U} \mathrm{mL}^{-1}$ after 7 days. PW concentrations above $55 \%$ showed no significant enhancement of the endoxylanase activity.

The 50-fold increased concentration of trace elements in the medium led to overall slightly higher enzymatic activities, but the difference was only significant for the endoglucanase activities at day 5 compared to the $1 \mathrm{x}$ control.

These results indicate that it is possible to replace some of the salts, Avicel, and trace elements present in MA medium by PW while maintaining the enhanced endoglucanase and endoxylanase activities up to $55 \%$ raw PW. However, as demonstrated by the 50x trace elements control, the growth enhancement seen in the PW cultivations can only partially be explained by the increased concentration in salts or trace elements. Nevertheless, no significant inhibition was observed due to the surplus of iron.

\section{Liquid cultivation with addition of free sugars simulating $25 \%$ PW}

To determine whether the free sugars present in the PW contribute to the observed enhanced enzymatic activities, we simulated the conditions present in the $25 \%$ PW by supplementing MA media with glucose, fructose, arabinose, galactose, and cellobiose in the respective concentrations (Fig. $3 \mathbf{b}$ ). The addition of free sugars to the cultivation medium resulted in no significant difference compared to the control condition with only Avicel (Fig. 4c). On the other hand, the addition of $25 \%$ PW supernatant recurrently resulted in significantly higher enzymatic activities compared to the two conditions without PW. This suggests that the free sugars in PW are not responsible for the observed beneficial effects of PW during the cultivations.

\section{Liquid cultivation with PW solids as C-source}

To estimate to what extent T. reesei RUT-C30 can use the PW solids as a carbon source and inducer, liquid cultures were prepared with $1 \%$ ball-milled PW solids, non-pressed Douglas-fir wood and Avicel as standard carbon source. Although the fungus seemed to grow, there was a clear difference in the development of the fungal biomass in the liquid cultures with PW solids and Douglas-fir wood vs. the Avicel-grown cultures (Fig. 5 b - d) and almost no enzymatic activities could be measured in the culture 
supernatants, even after 10 days (Fig. 5a). These results suggest that $T$. reesei is unable to utilize the PW solids or the Douglas-fir wood powder as a carbon source.

\section{Growth rate of several basidiomycetes in the presence of PW}

The growth rate of a series of wood-degrading basidiomycetes was measured on agar plates containing yeast malt extract agar (YEMA) supplemented with PW from Douglas-fir ( $25 \%$ and $75 \% \mathrm{v} / \mathrm{v}$ ) to assess the potential of wood PW as a substrate for lignocellulolytic fungi (Fig. 6a). Considering the ability of the tested strains to degrade lignin, we decided to use a batch of PW from Douglas-fir wood chips but with bark (PWB), which had a darker color and higher organic load (Additional file: Fig. S2).

We found that PWB enhanced the growth rates of all tested white rot fungi but not for the brown rot Rhodonia placenta. The strongest improvement was observed for Pleurotus ostreatus, for which the growth rate was accelerated from $0.18 \mathrm{~mm} \mathrm{~h}^{-1}(0 \% \mathrm{PW})$ to $0.54 \mathrm{~mm} \mathrm{~h}^{-1}$ (25\% PWB), representing a 3-fold improvement over YEMA. Despite showing a less drastic effect, a clear tendency of faster growth with increasing PWB concentrations was also observed for the used strains of Dentipellis fragilis, Schizophyllum commune, Hericium coralloides and Trametes versicolor (Fig. 6a).

\section{Bio-clarification of the PW}

To assess the potential to reduce the turbidity of PW (with and without bark), as beneficial trait for biological wastewater treatment, we cultivated T. versicolor, G. applanatum, and P. chrysosporium in liquid cultures of PW supplemented with potato dextrose liquid medium (PDY) and measured the optical density of the culture supernatants. A turbidity reduction compared to controls incubated without fungal biomass was observed for all the tested strains in PW and PWB. The highest turbidity reduction was observed in T. versicolor cultures (Fig. 6b). Furthermore, all strains displayed a change in coloration of the PW, indicating the uptake, degradation or metabolization of some PW components (see Additional file: Fig. S4, Fig. S5).

\section{Discussion}

The optimization of the wood chip drying process by implementing mechanical drying in conventional sawmills could lead to higher energy efficiency and reduced fuel consumption during the drying process. Thus, this seemingly small improvement could have considerable effects on the entire sawmilling process [48]. The COD values of the PW are comparable with effluents seen in the pulp and paper industry (thermo-mechanical pulp processing effluents and black liquor), which cause considerable operating costs due to the requirement of wastewater treatment [49-53]. Therefore, the discharge and treatment of large PW volumes could require more energy than the energy saved by the mechanical drying compared to the conventional thermal drying, hence becoming a financial burden [18]. Although no correlation between the COD and the amount of dissolved and undissolved substances in the PW was 
observed, it could be used as an orientation value to estimate the PW quality. Thus, higher COD and PW volumes, which translate to higher concentrations of substrates, would be beneficial for fungal fermentations. In parallel, the utilization of the PW would reduce the need for freshwater in the fermentation process, which is an important aspect for a more sustainable industry [54].

Wood type, felling season, and the location in which the trees have been growing ultimately define the composition and concentration of dissolved substances in the PW $[55,56]$. A direct comparison of sugar concentrations found in the PW and literature values is limited, since the substances in the PW are not actively extracted using solvents, temperature, nor hydrolyzing the wood. Glucose and fructose can be found as free sugars in the xylem of Douglas-fir, although in low concentrations compared to the branches or foliage and it might vary depending on biotic and abiotic growth influencing factors $[56,57]$. We were unable to detect rhamnose in the PW, which coincides with the low rhamnose concentrations observed in Douglas-fir wood [58]. The occurrence of cellobiose, the characteristic building block of cellulose, shows that there is a certain mechanical degradation of the cell wall, because it is not a naturally occurring disaccharide in wood [59]. Although Douglas-fir as a typical softwood contains more mannan than xylan (see Additional file: Table S2), we observed considerably lower mannose concentrations compared to xylose within the PW (Fig. $\mathbf{3 b}$ ). Also the arabinose and galactose concentrations were higher than the expected concentrations found in wood compositional analyses [58, $60,61]$. The branched structure and the nature of the neighbouring molecules influences the stability of the hemicelluloses. It is therefore possible that mannose is more stably embedded in the cell wall than xylose and thus more resistant against extraction by mechanical pressure [61, 62].

One of the concerns of supplementing the PW to fungal media was the possible presence of bioactive substances, like phenolic compounds from lignin or tannins, that could inhibit fungal growth $[63,64]$. In contrast to the wood-degrading basidiomycetes, T. reesei RUT-C30 lacks significant capacity to degrade lignin [65]. Considering that bark is the most extractive-rich tissue of Douglas-fir, the growth experiments of $T$. reesei were made using PW from debarked wood chips, thus minimizing any unforeseen interaction with potential inhibitors [66-68].

One of the major limitations of the PW as a substrate for liquid cultures is the lack of a nitrogen source, which is indispensable for fungal growth and enzyme production. However, this is a common issue among lignocellulosic substrates from agro-industrial or industrial wastes, such as sugarcane bagasse, soybean hulls, pulp and paper sludges, and even pretreated wood chips [29, 69-71], the only exception being manure [72]. Compared to the aforementioned substrates, the PW is not a rich source of cellulose and hemicelluloses, hence the supplementation of a carbon source, like Avicel, is necessary. Despite this, the PW was able to significantly enhance the enzymatic activities in the culture supernatants when supplemented to the medium (Fig. 4a). In contrast to PW, the utilization of several agro-industrial and industrial wastes has some limitations regarding the production of cellulolytic enzymes. The utilization of sugarcane bagasse and molasses often requires genetic strain optimization to overcome the effect of repressing sugars or the utilization of sucrose [29]. In the case of waste paper sludge, nonproductive binding of the substrate or inhibition from mineral paper additives are factors that render this substrate 
unsuitable for the enzyme production $[69,73]$. Similarly, steam-pretreated wood as a carbon source and inducer for enzyme production is limited by the presence of inhibiting sugar degradation products [71]. Sophorose and lactose are more suitable supplements for the production of cellulases in $T$. reesei as soluble inducers and carbon sources [74]. However, sophorose is prohibitively expensive and lactose, although cheap and largely available, induces only a limited amount of cellulases compared to cellulosic substrates [75-78].

The presence of lignin in the PW solids was confirmed by Py-GC/MS of the acid insoluble residues (Fig. $2 f)$, corresponding to typical lignin fragments found in pyrolyzed Douglas-fir wood [79, 80]. Additionally, the presence of some small phenolic substances and one characteristic flavonoid found in Douglas-fir, taxifolin, was confirmed in the methanolic fraction separated with SPE (C18 silica) of the dissolved substances in the PW. However, contrary to the literature reports, no substantial inhibition of endoglucanase activity and only a slight reduction of endoxylanase activity was observed, despite the presence of phenolic substances in the PW (see Additional file: Fig. S3) [66, 81-83]. Moreover, the lack of nutrients, especially a nitrogen source, had a stronger influence on the growth of $T$. reesei than the presence of PW (Fig. 3a). These results indicate that the concentration of potentially inhibiting compounds was insufficient to cause significant inhibition of $T$. reesei enzymes.

At low PW concentrations (25-55\% PW) the enhancing effect for enzyme production was similar for the cultivation with PW supernatant and with raw PW. The enzymatic activity of the cultures with PW was consistently higher after 3 days of cultivation compared to the control, even after the replacement of salts and trace elements (Fig. 4b). The consistent results suggest that the addition of $25-55 \%$ PW to the cultivation medium has a stronger effect on the enzymatic activities than varying the concentration of salts or trace elements in the medium (Fig. $\mathbf{4 a}$ - b). On the other hand, at higher concentrations $(75-100$ $\% \mathrm{PW}$ ) the measured enzymatic activities were less consistent. The endoxylanase activity was the most affected by the increased concentration of raw PW (Fig. 4b) compared to the same conditions with PW supernatant (Fig. 4a). Since the ion concentrations had no measurable effect on the enzymatic activities, the only difference between the PW supernatant and raw PW was the presence of PW solids.

The carbon source and inducer molecules constitute a major cost factor in the production of lignocellulolytic enzymes, and thus finding cheaper alternatives would be beneficial [29, 84]. The (partial) replacement of Avicel by the solids in PW has the potential to reduce some of the costs. However, $T$. reesei RUT-C30 was unable to grow on PW solids as sole carbon source as well as on non-pressed Douglas-fir wood powder (Fig. 5a), suggesting that the cellulose in the solids is too difficult for T. reesei to access efficiently in comparison to the microcrystalline cellulose of Avicel [65]. This observation is also in line with reports about Trichoderma spp. preferably growing on wood that has been previously degraded or pre-treated either chemically or by other fungi $[85,86]$. Therefore, the reduced concentration of Avicel in the cultivations with raw PW-replaced media could have contributed to the reduced endoxylanase activity at higher PW concentrations in the late stages of the fermentations. Moreover, the measurable reduction of the endoxylanase activity in presence of PW (Additional file: Fig. S3) suggests that inhibitory effects might also be due to direct interactions of PW components with the secreted enzymes. 
Lignin has been suggested to bind hydrophobic faces such as for example on the cellulose-binding module of cellulases, thus inactivating the enzymes by non-productive binding [87-90]. Consequently, it is possible that enzymes bound to the surface of the PW solids, thus reducing the enzymatic activity of the culture supernatants at higher concentrations of raw PW (Fig. 4b) [89]. In addition to that, several phenolic compounds generated from lignin degradation have been reported to inhibit a GH11 endoxylanase from Thermobacillus xylanilyticus in a non-competitive multisite mechanism [91]. This suggests that some components in the PW might interact specifically with the secreted endoxylanases. On the other hand, phenolic substances in the black liquor from the Kraft pulping process have been reported to modify the protein structure of commercial xylanases, enhancing the hydrolysis of xylan [92]. This might have contributed to the enhanced activities seen at low PW concentrations (25-55\%), while at higher PW concentrations ( $75-100 \%$ ) the positive effects are offset by the non-productive binding on the PW solids and inhibition by other substances.

Cellobiose is known to induce the production of cellulases in T. reesei [93]. Furthermore, oligosaccharides derived from cellulose have a strong induction effect on the cellulase expression [94, 95]. However, the addition of surplus cellobiose and other monosaccharides to the cultivation medium corresponding to the concentrations found in 25 \% PW showed no significant effect by itself (Fig. 4c). Consequently, neither the dissolved sugars, nor the suspended solids of the PW were found to be causative for the positive effects of the PW cultures, and that the minerals had only a small positive influence (Fig. 4b). Therefore, we suggest that the enhancing effect might come from other, so far unidentified, organic molecules dissolved in the PW. There is a possibility that some components in the PW also directly interact with some signaling pathways or induce some modifications on the hyphal cell walls, similar to N, Ndimethylformamide, which was reported to enhance cellulase production via calcium signaling and permeabilization of the hyphal cell wall in T. reesei RUT-C30 [96]. It has been suggested that the micromorphology of $T$. reesei influences the enzyme productivity [97]. Although the micromorphology of T. reesei RUT-C30 was not measured in this study, an analysis could reveal if the enhanced enzymatic productivity seen in the PW cultures is related to changes in hyphal morphology. A deeper understanding of the composition of the organic fraction of the PW combined with an RNAseq analysis of T. reesei RUTC30 in presence of PW to identify internal signaling processes would allow to elucidate how the PW interacts with the fungus and induces higher endoglucanase activities.

The growth experiments on agar plates with the white rots $P$. ostreatus, $T$. versicolor, $D$. fragilis, $S$. commune, $H$. coralloides and the brown rot $R$. placenta were made using PWB as a supplement, which contained more dissolved substances than PW (Additional file: Fig. S2, Table S1). The tested white rot strains showed a significant growth enhancement regardless of the PWB concentration, except for $D$. fragilis, where an increment from $25 \%$ to $75 \%$ caused a growth rate reduction (Fig. 6a). Interestingly, $R$. placenta, the only brown rot strain that was tested, showed no significant growth rate change in the presence of PWB. While more species will have to be tested, it is intriguing to speculate that the differences seen among the basidiomycetes is related to the presence or absence of ligninolytic enzymes $[35,36]$. Altogether, no growth inhibition was observed on all the tested fungal strains, hence the PW of Douglas-fir was considered non-toxic. A deeper examination of the effect of PWB components on the 
transcriptome of white rots would be required to determine the effect of PW on the expression of lignindegrading peroxidases of basidiomycetes.

One interesting alternative to the conventional wastewater treatment that might offer a quick solution for the high turbidity and high COD would be fungal-assisted bio-clarification of wood PW. Our results demonstrated that the turbidity was substantially reduced after a few days of cultivation (Fig. $\mathbf{3 b}$ ). Fungal mycelia entrapping the suspended solids in the PW is a practical solution to overcome longer settling times or extensive filtration [98]. The advantage of using wood-degrading basidiomycetes goes beyond the capture of suspended solids. We observed a decrease in absorption over the entire visible spectrum $(230-800 \mathrm{~nm}$ ) (Additional file 4; Figure S3), indicating some degradation of dissolved substances in the PW probably due to the secretion of ligninolytic enzymes [99-101], which nevertheless needs to be verified.

\section{Conclusion}

The PW of Douglas-fir wood chips is a complex sawmill side stream with a high COD, demanding costly wastewater treatment. However, several of the dissolved components as well as the solids are also part of conventional fungal growth media, and despite the presence of potential phenolic inhibitors, the PW was found to be a suitable non-toxic media supplement for several basidiomycetes as well as the industrially employed ascomycete $T$. reesei. The supplementation of cleared PW to liquid cultures of $T$. reesei RUT-C30 reduced the lag-phase and significantly enhanced the endoglucanase and endoxylanase activities in the supernatant. The supplementation of $55 \%$ PW to the cultivation media allowed the replacement of $100 \%$ trace elements $\left(\mathrm{Fe}^{2+}, \mathrm{Mn}^{2+}, \mathrm{Zn}^{2+}\right)$ of the conventional MA medium as well as $12 \%$, $13 \%$ and $6 \%$ of $\mathrm{Ca}^{2+}, \mathrm{Mg}^{2+}$, and $\mathrm{K}^{+}$, respectively, without losing the positive influence on enzyme production. Furthermore, PW allowed to replace an equal volume of fresh water. The utilization of PW in fungal cultivations could therefore combine a bio-clarification of this sawmill effluent with the creation of added-value by lowering costs of media formulations and an increased product yield.

A further analysis of the molecular pathways being activated by PW as well as an advanced qualitative and quantitative chemical analysis will therefore be crucial to understand the mechanisms of the positive effects seen in this study and pinpoint the responsible compounds for the growth-enhancing effects of the PW on the tested fungal strains.

\section{Materials And Methods}

\section{Press water samples}

The press water used in this study was obtained by pressing debarked wood chips of Pseudotsuga menziesii (Douglas-fir) with a roller press (wood chips squeezer) located at Bohnert Technik GmbH in Seebach, Germany. Douglas-fir wood chips with and without bark were obtained from local sawmills. The wood chips were fed evenly on a patented plate conveyor chain, which passes between two large rollers 
(Bohnert 2011). The chain helps deliver the wood chips to the pressing zone and at the same time facilitates the drainage of press water through narrow gaps between the chain links. The press water (PW) was collected directly beneath the pressing zone in large container. The PW was thoroughly homogenized before fractionation into $1 \mathrm{~L} \mathrm{HDPE}$ bottles. The press water was always stored at $-20^{\circ} \mathrm{C}$ if not otherwise mentioned.

\section{Physico-chemical analysis of PW}

The PW was centrifuged at 4000 rcf for 15 min in a centrifuge (Heraeus Megafuge 40R, Thermo Scientific). The PW supernatant was carefully decanted, aliquots of $100 \mathrm{~mL}$ were transferred to lyophilisation flaks, and the same was done for the sediment. The total mass content was determined gravimetrically after drying the samples in a freeze dryer (Christ Alpha 1-2LDplus). Fine particles that remained suspended after the centrifugation were quantified gravimetrically using cellulose acetate filter membranes with pore size of $0.45 \mu \mathrm{m}$ (Sartorius).

\section{Particle size distribution}

A laser diffraction system HELOS (Sympatec, Germany) with the RHODOS dispersing unit was used to measure the particle size distribution over a wide range of sizes of the PW supernatant.

\section{Chemical oxygen demand}

The chemical oxygen demand (COD) and dissolved ions concentrations were measured by the Chair of Urban Water Systems Engineering at the Technical University of Munich, according to the German standard methods for the examination of water [102-105].

\section{Acid hydrolysis}

The determination of acid insoluble residues in the solids of the press water was conducted according to the standard procedures TAPPI T 249 and T 222. Briefly, $1 \mathrm{~g}$ of the lyophilized and homogenized PW solids was incubated for $2 \mathrm{~h}$ with $15 \mathrm{~mL}$ of $72 \%$ sulphuric acid in a water bath at $20^{\circ} \mathrm{C}$. Then, the acid was diluted to $3 \%$ and incubated for $4 \mathrm{~h}$ at $100{ }^{\circ} \mathrm{C}$. After hydrolysis the sample was filtered, the acidinsoluble residue (AIR) was determined gravimetrically and the acid-soluble aromatics (ASA was determined spectroscopically at $205 \mathrm{~nm}\left(\varepsilon 110 \mathrm{~g} \mathrm{~L}^{-1} \mathrm{~cm}^{-1}\right)$ [106-108] .

\section{Py-GC/MS and GC/MS analysis and sample preparation}

Solid samples were measured using the pyrolysis gas chromatography coupled to a mass spectrometer (Py-GC/MS), VLMSD 5975C (Agilent Technologies) equipped with a VF17 MS $30 \mathrm{~m} \times 250 \mu \mathrm{m} \times 0.25 \mu \mathrm{m}$ column (Agilent Technologies). The pyrolysis was performed in a single shot analysis at $450{ }^{\circ} \mathrm{C}$ for $0.2 \mathrm{~min}$. For liquid samples, PW was filtered followed by an extraction step using a SPE C18ec cartridge 
and methanol to elute the hydrophobic substances (Chromabond, Macherey-Nagel). The GC/MS conditions: Inj. $300^{\circ} \mathrm{C}$ with a split of $40: 1$ and temperature program: $T_{1}=100^{\circ} \mathrm{C}$ for $1 \mathrm{~min}, \mathrm{R}=10{ }^{\circ} \mathrm{C} / \mathrm{min}$, $\mathrm{T}_{2}=300^{\circ} \mathrm{C}$ for $4 \mathrm{~min}$. Liquid samples were silylated prior to injection. The mass spectra were evaluated using the NIST MS library (NIST20). Taxifolin, was verified and quantified using a calibration curve with a reference (Sigma-Aldrich).

\section{HPAEC-PAD analysis of the PW}

Free neutral sugars (list all sugars) were determined on a Dionex ICSW 3000 HPAEC-PAD instrument setup with a Dionex AS Autosampler, a Dionex gradient mixer GM-3 (Dionex Corp., California USA) and a CarboPacPA1 preparative IC column $(4 \times 250 \mathrm{~mm})$ equipped with a CarboPacPA1 standard bore guard column ( 4 × $50 \mathrm{~mm}$ ) (Thermo Fisher Scientific Inc., Massachusetts USA). The analysis was carried out with a 27 min isocratic method with a $10 \mathrm{mM}$ sodium hydroxide solution for monosaccharides in deionized water with low total organic carbon at $1 \mathrm{~mL} \mathrm{~min}{ }^{-1}$ flow rate and $30^{\circ} \mathrm{C}$. For the analysis of disaccharides, the sodium hydroxide concentration was elevated to $100 \mathrm{mM}$.

The PW samples were filtered with a PES membrane with a pore size of $0.2 \mu \mathrm{m}$ and cleaned using an anion exchange SPE cartridge (Strata XA, Phenomenex) following the protocol of the manufacturer. The samples were further diluted with $\mathrm{ddH} 2 \mathrm{O}$ before measurement in duplicate.

\section{Strain cultivation}

T. reesei strain RUT-C30 was propagated on potato dextrose agar (Carl Roth) plates in the dark at $30{ }^{\circ} \mathrm{C}$ for two days, then switched to constant light at $25^{\circ} \mathrm{C}$ for conidiation. All liquid media cultivations were carried out in $250 \mathrm{~mL}$ flasks without baffles containing $50 \mathrm{~mL}$ medium and shaken at $250 \mathrm{~min}^{-1}(25 \mathrm{~mm}$ throw) and at $30^{\circ} \mathrm{C}$ in darkness, if not otherwise mentioned. For the inoculation, a respective volume of conidial suspension was added after optical density measurement to a final concentration of $10^{6}$ conidia $\mathrm{ml}^{-1}$. Cultures were always grown in triplicates if not otherwise mentioned.

Schizophyllum commune and Ganoderma applanatum were isolated by Philipp Benz in Freising, Germany. Dentipellis fragilis and Hericium coralloides were isolated by Markus Blashke in the natural forest reserve Gitschger, Germany. Pleurotus ostreatus FPRL 40C, Trametes versicolor BAM116 (CTB863) and Rhodonia placenta BAM 113 (FPRL 280) were obtained from the German Federal Institute for Materials Research (BAM). Phanerochaete chrysosporium (DMSZ 1556) was obtained from the German Collection of Microorganisms and cell Cultures $\mathrm{GmbH}$. Basidiomycete strains were cultivated on yeast malt extract agar (YMEA) containing $10 \mathrm{~g} \mathrm{~L}^{-1}$ glucose, $5 \mathrm{~g} \mathrm{~L}^{-1}$ peptone, $3 \mathrm{~g} \mathrm{~L}^{-1}$ malt extract, $3 \mathrm{~g} \mathrm{~L}^{-1}$ yeast extract and $20 \mathrm{~g} \mathrm{~L}^{-1}$ agar until the mycelium covered the entire plate.

\section{Phenotype analysis and growth rate on PW agar}


The agar plates used for the phenotype experiments consisted of $2 \%$ agar adjusted to $\mathrm{pH}$ 5.0. The PW agar was prepared either without or with the addition of Mandels-Andreotti (MA) medium components and no addition of glucose [40]. MA minimal media agar was prepared with $0.2 \mathrm{~g} \mathrm{~L}^{-1}$ glucose to simulate the glucose concentrations present in the PW. The plates were inoculated with $2 \mu \mathrm{l}$ from a spore solution containing $0.5 \times 10^{6}$ conidia $\mathrm{ml}^{-1}$.

After ten days of cultivation at $25^{\circ} \mathrm{C}$ with constant light. The conidia were harvested by washing the agar plates with $5 \mathrm{ml} \mathrm{H}_{2} \mathrm{O}$ ten times covering one half of the plate and then repeating the procedure with another $5 \mathrm{ml}$ of $\mathrm{H}_{2} \mathrm{O}$ for the other half of the plate. Conidia were filtered with glass wool, centrifuged, and finally resuspended in $5 \mathrm{ml} \mathrm{H}_{2} \mathrm{O}$. The quantification was done by measuring the $\mathrm{OD}$ at $600 \mathrm{~nm}$.

For the growth analysis of the Basidiomycete strains, $5 \mathrm{~mm}$ plugs were cut out of pre-cultures using a coring tool and then transferred to the middle of new plates with YMEA with no PW, with $25 \%$ or $75 \%$ (v/v) PW from Douglas-fir wood chips with bark (Additional file 1; Figure S1). All plates were prepared with $20 \mathrm{~mL}$ agar and the plugs were cut from the peripheral growth zone of the fungal cultures. The plates were incubated at $25^{\circ} \mathrm{C}$. The growth was observed daily and recorded with digital photographs using a camera equipped with a $60 \mathrm{~mm}$ macro lens (Nikon) next to a reference scale. The growth rate was calculated from the fitted curve of biological triplicates and technical replicates were measured in different directions.

\section{Press water liquid media for cellulase production}

For the cultivation with PW supernatant, the raw PW was centrifuged at 4000 rcf for 15 min (Heraeus Megafuge 40R, Thermo Scientific) and the supernatant was decanted to be used in the liquid medium. The PW supernatant was diluted with $\mathrm{ddH}_{2} \mathrm{O}$ to different concentrations, namely $25 \%, 50 \%, 75 \%$, and $100 \%(\mathrm{v} / \mathrm{v})$. The complete MA medium was added to each PW condition, so that only $\mathrm{ddH}_{2} \mathrm{O}$ was replaced in each condition. All liquid media were adjusted to $\mathrm{pH} 5.0$ with $0.1 \mathrm{M}$ phosphate-citrate buffer and $1 \%(\mathrm{w} / \mathrm{v})$ Avicel PH-101 (Sigma-Aldrich) was used as a carbon source and inducer, if not otherwise mentioned.

The sedimented PW solids, after the centrifugation step mentioned above, were used as a carbon source, and compared to Avicel and wood powder obtained from unpressed Douglas-fir wood chips. The PW solids were washed with $\mathrm{ddH}_{2} \mathrm{O}$ and dried overnight in a drying oven. To achieve a particle size like that of Avicel $(500 \mu \mathrm{m})$, we treated the PW solids and the Douglas-fir powder in a ball-mill (MM200, Retsch). Each flask with MA medium contained $1 \%(\mathrm{w} / \mathrm{v})$ of the respective solid as a carbon source.

The cultivation with PW with replacement of salts and carbon source was carried out with uncentrifuged PW in different concentrations. The percentage of salts, trace elements and Avicel to be replaced were calculated based on the molar concentrations of dissolved ions (Table 1) and the total hydrolysable solids in the PW (Fig. 2e). A PW concentration of $55 \%(\mathrm{v} / \mathrm{v})$ was chosen as the minimal concentration 
needed to achieve a complete replacement of trace elements. No trace elements were added to the conditions containing more than $55 \% \mathrm{PW}$. Only $\left(\mathrm{NH}_{4}\right)_{2} \mathrm{SO}_{4}$, peptone, urea, and $\mathrm{CoCl}_{2}$ were not replaced in any condition (Table 2).

Table 1 lon concentration in PW and relative to Mandels-Andreotti medium (MA)

\begin{tabular}{|lllll|}
\hline & \multicolumn{3}{c}{$\mathrm{PW}$} & \multicolumn{3}{l|}{$\mathrm{MA}$} & \\
\cline { 2 - 5 } & $\mathrm{mg} \mathrm{L}^{-1}$ & $\mathrm{mM}$ & $\mathrm{mM}$ & covered by PW, \% \\
\hline $\mathrm{PO}_{4}{ }^{3-}$ & 16.90 & 0.18 & 14.70 & 1.21 \\
\hline $\mathrm{SO}_{4}{ }^{2-}$ & 38.00 & 0.40 & 11.85 & 3.34 \\
\hline $\mathrm{NH}_{4}{ }^{+}$ & 1.43 & 0.08 & 21.19 & 0.37 \\
\hline $\mathrm{NO}_{3}{ }^{-}$ & $<5$ & - & - & - \\
\hline $\mathrm{Na}^{+}$ & 4.28 & 0.19 & - & - \\
\hline $\mathrm{Ca}^{2+}$ & 49.20 & 1.23 & 2.72 & 45.13 \\
\hline $\mathrm{Mg}^{2+}$ & 14.60 & 0.60 & 1.22 & 49.38 \\
\hline $\mathrm{K}^{+}$ & 130.00 & 3.33 & 14.70 & 22.62 \\
\hline Trace $^{2}$ elements & & & \\
\hline $\mathrm{Fe}^{2+}$ & 20.10 & 0.36 & 0.02 & 2001.60 \\
\hline $\mathrm{Mn}^{2+}$ & 4.83 & 0.09 & 0.01 & 874.88 \\
\hline $\mathrm{Zn}^{2+}$ & 0.61 & 0.01 & 0.005 & 184.86 \\
\hline
\end{tabular}

Table 2 Mandels-Andreotti medium constituents modified for the cultivation of T. reesei with raw PW (\% $\mathrm{v} / \mathrm{v}$ ) with replacement of Avicel 


\begin{tabular}{|c|c|c|c|c|c|c|c|}
\hline \multirow[t]{2}{*}{ Components } & \multirow[t]{2}{*}{ Unit } & \multicolumn{2}{|c|}{ MA media } & \multicolumn{4}{|c|}{ PW media } \\
\hline & & $1 x$ & $50 \times \mathrm{TE}$ & $25 \%$ & $55 \%$ & $75 \%$ & $100 \%$ \\
\hline \multicolumn{8}{|l|}{ Salt solution } \\
\hline $\mathrm{KH}_{2} \mathrm{PO}_{4}$ & $\mathrm{~g} \mathrm{~L}^{-1}$ & 2.00 & 2.00 & 1.89 & 1.75 & 1.66 & 1.55 \\
\hline $\mathrm{CaCl}_{2} \cdot 2 \mathrm{H}_{2} \mathrm{O}$ & $\mathrm{g} \mathrm{L}^{-1}$ & 0.40 & 0.40 & 0.35 & 0.3 & 0.26 & 0.22 \\
\hline $\mathrm{MgSO}_{4} \cdot 7 \mathrm{H}_{2} \mathrm{O}$ & $\mathrm{g} \mathrm{L}^{-1}$ & 0.30 & 0.30 & 0.26 & 0.22 & 0.19 & 0.15 \\
\hline \multicolumn{8}{|l|}{ Trace elements } \\
\hline $\mathrm{FeSO}_{4} \cdot 7 \mathrm{H}_{2} \mathrm{O}$ & $\mathrm{mg} \mathrm{L}^{-1}$ & 5.00 & $250(* 350)$ & 5.00 & - & - & - \\
\hline $\mathrm{MnSO}_{4} \cdot \mathrm{H}_{2} \mathrm{O}$ & $\mathrm{mg} \mathrm{L}^{-1}$ & 1.60 & 80 & 1.60 & - & - & - \\
\hline $\mathrm{ZnSO}_{4} \cdot 7 \mathrm{H}_{2} \mathrm{O}$ & $\mathrm{mg} \mathrm{L}^{-1}$ & 1.40 & 70 & 1.40 & - & - & - \\
\hline \multicolumn{8}{|l|}{ Carbon source } \\
\hline PW & $(v / v) \%$ & - & & 25 & 55 & 75 & 100 \\
\hline Avicel & $\mathrm{g} \mathrm{L}^{-1}$ & 10 & & 9.57 & 9.05 & 8.7 & 8.27 \\
\hline
\end{tabular}

*Iron concentration used in the iron-enriched control medium MA 50x TE + 20x Fe

Cobalt had to be supplemented to the medium, since considerable differences in the cellulase. 50x TE: 50 times the concentration of trace elements (TE) was used as a control.

The addition of free sugars to the cultivation medium was based on the sugar concentration measured in the PW (Additional file: Fig. S1). Glucose $\left(0.061 \mathrm{~g} \mathrm{~L}^{-1}\right)$, fructose $\left(0.150 \mathrm{~g} \mathrm{~L}^{-1}\right)$, galactose $\left(0.022 \mathrm{~g} \mathrm{~L}^{-1}\right)$, arabinose $\left(0.007 \mathrm{~g} \mathrm{~L}^{-1}\right)$, cellobiose $\left(0.003 \mathrm{~g} \mathrm{~L}^{-1}\right)$, xylose $\left(0.003 \mathrm{~g} \mathrm{~L}^{-1}\right)$, concentrations that correspond to 25 $\% \mathrm{PW}$, were added to MA medium with $1 \%$ Avicel and autoclaved. MA medium with no sugars and $25 \%$ PW supernatant, both with $1 \%$ Avicel, were used as control.

\section{Enzymatic assays}

Endo-1,4- $\beta$-D-glucanase and endo-1,4- $\beta$-D-xylanase activity assays were carried out according to the protocols (S-ACMC and S-AXBL) of the manufacturer (Megazyme, Ireland), slightly modified and adapted for a 96-well microplate. Each sample was tested in technical duplicate. The mean and the standard deviation are calculated from the biological triplicates and technical duplicates.

Inhibition of the enzymatic reactions in the presence of PW was verified using the same method as described above. As enzyme we used supernatant of a 5-day old T. reesei RUT-C30 culture grown with $1 \%$ 
Avicel. Each reaction consisted of $10 \mu$ l enzyme and increasing concentrations of PW, namely $20 \%(\mathrm{v} / \mathrm{v})$ and $60 \%(\mathrm{v} / \mathrm{v})$. The reaction volume was adjusted to $25 \mu \mathrm{l}$ with $\mathrm{ddH}_{2} \mathrm{O}$. These tests were performed in 6 technical replicates for each condition.

\section{Bio-clarification of PW}

Liquid pre-cultures of $T$. versicolor, G. applanatum and P. chrysosporium, were made in shaking flasks with $50 \mathrm{~mL}$ potato dextrose yeast (PDY) in $250 \mathrm{~mL}$ Erlenmeyer flasks until enough biomass was formed. These strains were chosen due to their fast growth in liquid media. The biomass was then homogenized using an Ultra Turrax (IKA Werke $\mathrm{GmbH}$, Germany) and transferred to the PDY media containing $50 \%$ PW or PWB. The cultures were inoculated with $10 \%$ biomass suspension and were cultivated in $100 \mathrm{~mL}$ Erlenmeyer flasks with $30 \mathrm{~mL}$ medium for 4 days at $28^{\circ} \mathrm{C}, 100 \mathrm{rpm}(50 \mathrm{~mm}$ throw). As a control condition PW and PWB flasks without fungal biomass were incubated together with the cultures. The entire volume of the cultures was collected in centrifugation tubes and centrifuged $2 \mathrm{~min}$ at $1000 \mathrm{rcf}$. The supernatants were carefully transferred to cuvettes and the OD was measured at $600 \mathrm{~nm}$ to calculate the turbidity change against the control condition.

\section{Statistical analyses}

Statistical analyses were performed by applying one-way repeated measures analysis of variance (ANOVA) followed by Dunnett's test using the growth condition without PW as control in OriginPro 2021 (OriginLab Corporation). Significance level of $p<0.05$.

\section{Declarations}

\section{Authors' contributions}

JPB, EWH and KR conceived of the study and supervised it. MR, JPB and EWH designed the experiments. $M R$ and $R G$ performed the experiments and acquired the data. MR, RG, EWH and JPB analyzed and interpreted the data. MR drafted the manuscript, which was critically revised by JPB, RG, EWH and KR. All authors read and approved the final manuscript.

\section{Acknowledgements}

We want to thank Ralf Rosin (HFM, TUM) for his assistance with the photographs, Andreas Tenz for performing the pyrolysis GC/MS analyses and Claudia Strobel and Snezana Sajkas Sajdl for performing the acid hydrolysis and the compositional analysis. We also want to thank Johannes Bohnert (BohnertTechnik GmbH, Seebach) \& Christofer Gutmann (Pollux Edelstahlverarbeitung GmbH, Ottenhöfen) for the cooperation on their wood presses, for performing the mechanical drying of wood chips and for providing the PW samples.

\section{Competing interests}


The authors declare that they have no competing interests.

\section{Consent for publication}

Not applicable.

\section{Ethics approval and consent to participate}

Not applicable.

\section{Funding}

This research work is funded by the Bavarian State Ministry of Food, Agriculture and Forestry (Bayerisches Staatsministerium für Ernährung, Landwirtschaft und Forsten) and managed by the Bavarian State Institute of Forestry (Bayerische Landesanstalt für Wald und Forstwirtschaft (LWF)), Project number X043. The authors thank for financial support.

\section{References}

1. Döring P, Gieseking L, Mantau U. Sägeindustrie 2018: Einschnitt- und Produktions- volumen. Hamburg; 2020.

2. Gößwein S, Hiendlmeier S, Borchert H. Energieholzmarkt Bayern 2018; 2020.

3. Popadić R, Šoškić B, Milić G, Todorović N, Furtula M. Influence of the Sawing Method on Yield of Beech Logs with Red Heartwood. Drvna ind. 2014;65:35-42. doi:10.5552/drind.2014.1312.

4. FAO. Global Forest Products Facts and Figures. 2021. http://www.fao.org/forestry/statistics/80938/en/. Accessed 17 Jun 2021.

5. Li X-R, Koseki H, Momota M. Evaluation of danger from fermentation-induced spontaneous ignition of wood chips. Journal of Hazardous Materials. 2006;135:15-20. doi:10.1016/j.jhazmat.2005.11.034.

6. Heinek S, Polanz S, Huber MB, Hofmann A, Monthaler G, Fuchs HP, et al. Biomass Conditioning - An Investigation of the Degradation Process of Woodchips and Forest Residues during Storage in Western Austria. 21th European Biomass Conference At: Kopenhagen; 2013.

7. Hofmann N, Mendel T, Schulmeyer F, Kuptz D, Borchert H, Hartmann H. Drying effects and dry matter losses during seasonal storage of spruce wood chips under practical conditions. Biomass Bioenergy. 2018;111:196-205. doi:10.1016/j.biombioe.2017.03.022.

8. Kuptz D, Hofmann N, Mendel T, Lesche S, Riebler M, Schulmeyer F, et al. TFZ-Bericht 70: Effiziente Lagerungs- und Aufbereitungsverfahren für Holzhackschnitzel, Stand August 2020; 2020.

9. Schön C, Kuptz D, Mack R, Zelinski V, Loewen A, Hartmann H. Influence of wood chip quality on emission behaviour in small-scale wood chip boilers. Biomass Convers Biorefin. 2019;9:71-82. doi:10.1007/s13399-017-0249-7. 
10. Kuptz D, Schreiber K, Schulmeyer F, Lesche S, Zeng T, Ahrens F, et al. Evaluation of combined screening and drying steps for the improvement of the fuel quality of forest residue wood chipsresults from six case studies. Biomass Convers Biorefin. 2019;9:83-98. doi:10.1007/s13399-01900389-2.

11. Fagernäs L, Brammer J, Wilén C, Lauer M, Verhoeff F. Drying of biomass for second generation synfuel production. Biomass Bioenergy. 2010;34:1267-77. doi:10.1016/j.biombioe.2010.04.005.

12. Pang S, Mujumdar AS. Drying of Woody Biomass for Bioenergy: Drying Technologies and Optimization for an Integrated Bioenergy Plant. Drying Technol. 2010;28:690-701. doi:10.1080/07373931003799236.

13. Del Giudice A, Acampora A, Santangelo E, Pari L, Bergonzoli S, Guerriero E, et al. Wood Chip Drying through the Using of a Mobile Rotary Dryer. Energies. 2019;12:1590. doi:10.3390/en12091590.

14. Haygreen JG. Potential for compression drying of green wood chip fuel. Forest Products Journal. $1981 ; 31: 43-54$.

15. Lui Z, Haygreen JG. Drying rates of wood chips during compression drying. Wood Fiber Sci. 1985;17:214-27.

16. Zhao Y, Wang Z, lida I, Huang R, Lu J, Jiang J. Studies on pre-treatment by compression for wood drying I: effects of compression ratio, compression direction and compression speed on the reduction of moisture content in wood. J Wood Sci. 2015;61:113-9. doi:10.1007/s10086-014-1451$x$.

17. Laurila J, Havimo M, Lauhanen R. Compression drying of energy wood. Fuel Process Technol. 2014;124:286-9. doi:10.1016/j.fuproc.2014.03.016.

18. Frodeson S, Berghel J, Ståhl M, Granström K, Romlin C, Thelander A. The Potential for a Pellet Plant to Become a Biorefinery. Processes. 2019;7:233. doi:10.3390/pr7040233.

19. Yoshida T, Sasaki H, Takano T, Sawabe O. Dewatering of high-moisture wood chips by roller compression method. Biomass Bioenergy. 2010;34:1053-8. doi:10.1016/j.biombioe.2010.02.013.

20. Svensson H, Svensson B-M, Hogland W, Marques M. Acute Toxic Effects Caused by Leachate from Five Different Tree Species on Artemia Salina and Vibro Fischeri. J Biobased Mater Bioenergy. 2012;6:214-20. doi:10.1166/jbmb.2012.1202.

21. Hewitt LM, Kovacs TG, Dubé MG, MacLatchy DL, Martel PH, McMaster ME, et al. Altered reproduction in fish exposed to pulp and paper mill effluents: roles of individual compounds and mill operating conditions. Environ Toxicol Chem. 2008;27:682-97. doi:10.1897/07-195.1.

22. Focke, Jan, Schlör N, Renner A. Endbericht - InnoDry: Innovatives Verfahren zur Veredelung von Sägenebenprodukten zur Verbesserung der regionalen Absatzmöglichkeit und Versorgungssicherheit von Nah- und Fernwärmenetzen; 2014.

23. Kostamo A, Holmbom B, Kukkonen JVK. Fate of wood extractives in wastewater treatment plants at kraft pulp mills and mechanical pulp mills. Water Res. 2004;38:972-82.

doi:10.1016/j.watres.2003.10.051. 
24. Lacorte S. Organic compounds in paper-mill process waters and effluents. TrAC Trends in Analytical Chemistry. 2003;22:725-37. doi:10.1016/S0165-9936(03)01009-4.

25. Hatakka A, Kenneth EH. Fungal biodegradation of lignocelluloses. In: Hofrichter M, editor. Industrial Applications. 2nd ed. Berlin, Heidelberg: Springer-Verlag Berlin Heidelberg; 2010. p. 319-340.

26. Bischof RH, Ramoni J, Seiboth B. Cellulases and beyond: the first 70 years of the enzyme producer Trichoderma reesei. Microb Cell Fact. 2016;15:106. doi:10.1186/s12934-016-0507-6.

27. Kumar R, Singh S, Singh OV. Bioconversion of lignocellulosic biomass: biochemical and molecular perspectives. J Ind Microbiol Biotechnol. 2008;35:377-91. doi:10.1007/s10295-008-0327-8.

28. Paloheimo M, Haarmann T, Mäkinen S, Vehmaanperä J. Production of Industrial Enzymes in Trichoderma reesei. In: Schmoll M, Dattenböck C, editors. Gene Expression Systems in Fungi: Advancements and Applications. Cham: Springer International Publishing; 2016. p. 23-57. doi:10.1007/978-3-319-27951-0_2.

29. Ellilä S, Fonseca L, Uchima C, Cota J, Goldman GH, Saloheimo M, et al. Development of a low-cost cellulase production process using Trichoderma reesei for Brazilian biorefineries. Biotechnol Biofuels. 2017;10:30. doi:10.1186/s13068-017-0717-0.

30. Klein-Marcuschamer D, Oleskowicz-Popiel P, Simmons BA, Blanch HW. The challenge of enzyme cost in the production of lignocellulosic biofuels. Biotechnol Bioeng. 2012;109:1083-7. doi:10.1002/bit.24370.

31. Gebremariam SN, Hvoslef-Eide T, Terfa MT, Marchetti JM. Techno-Economic Performance of Different Technological Based Bio-Refineries for Biofuel Production. Energies. 2019;12:3916. doi:10.3390/en12203916.

32. Peterson R, Nevalainen H. Trichoderma reesei RUT-C30--thirty years of strain improvement. Microbiology (Reading, Engl ). 2012;158:58-68. doi:10.1099/mic.0.054031-0.

33. Hatakka Al, Uusi-Rauva AK. Degradation of 14C-labelled poplar wood lignin by selected white-rot fungi. Eur J Appl Microbiol Biotechnol. 1983;17:235-42. doi:10.1007/BF00510422.

34. Ayuso-Fernández I, Rencoret J, Gutiérrez A, Ruiz-Dueñas FJ, Martínez AT. Peroxidase evolution in white-rot fungi follows wood lignin evolution in plants. PNAS. 2019;116:17900-5. doi:10.1073/pnas.1905040116.

35. Ohm RA, Riley R, Salamov A, Min B, Choi I-G, Grigoriev IV. Genomics of wood-degrading fungi. Fungal Genet Biol. 2014;72:82-90. doi:10.1016/j.fgb.2014.05.001.

36. Riley R, Salamov AA, Brown DW, Nagy LG, Floudas D, Held BW, et al. Extensive sampling of basidiomycete genomes demonstrates inadequacy of the white-rot/brown-rot paradigm for wood decay fungi. Proceedings of the National Academy of Sciences. 2014;111:9923-8. doi:10.1073/pnas.1400592111.

37. Chen H, Zhao X, Liu Y, Kong F, Ji X. Ligninases remove phenolic inhibitors and facilitate yeast growth in lignocellulosic hydrolysate. Holzforschung. 2019;73:681-7. doi:10.1515/hf-2018-0180.

38. Tuomela M, Oivanen P, Hatakka A. Degradation of synthetic 14C-lignin by various white-rot fungi in soil. Soil Biol Biochem. 2002;34:1613-20. doi:10.1016/S0038-0717(02)00145-1. 
39. Fang Z, Liu X, Chen L, Shen Y, Zhang X, Fang W, et al. Identification of a laccase Glac15 from Ganoderma lucidum 77002 and its application in bioethanol production. Biotechnol Biofuels. 2015;8:54. doi:10.1186/s13068-015-0235-x.

40. Mandels $M$, Andreotti R. Problems and challenges in the cellulose to cellulase fermentation. Process Biochem. 1978;13:6-13.

41. Chen $Y$, Shen $Y$, Wang W, Wei D. Mn2+ modulates the expression of cellulase genes in Trichoderma reesei Rut-C30 via calcium signaling. Biotechnol Biofuels. 2018;11:54. doi:10.1186/s13068-0181055-6.

42. Morikawa Y, Ohashi T, Mantani O, Okada H. Cellulase induction by lactose in Trichoderma reesei PC3-7. Appl Microbiol Biotechnol. 1995;44:106-11. doi:10.1007/BF00164488.

43. Souza MF de, Da Silva Bon EP, Da Silva AS. Production of cellulases and $\beta$-glucosidases by Trichoderma reesei Rut C30 using steam-pretreated sugarcane bagasse: an integrated approach for onsite enzyme production. Braz. J. Chem. Eng. 2021;38:435-42. doi:10.1007/s43153-021-00114-5.

44. Henin JM, Pollet C, Schmitt U, Blohm JH, Koch G. Technological properties of Douglas-fir wood. In: Spiecker H, Lindner M, Schuler JK, editors. Douglas-fir: An option for Europe. Joensuu: European Forest Institute; 2019. p. 89-97.

45. Spiecker H, Lindner M, Schuler JK, editors. Douglas-fir: An option for Europe. Joensuu: European Forest Institute; 2019.

46. Thünen-Institut. Forest Development- and Timber Volume Modeling 2012: https://bwi.info, 43Z1PZ_P583of_1252_L40id, Predicted increment of growing stock $\left[\mathrm{m}^{3} / \mathrm{ha}^{*}\right.$ a] by tree species group and projection period. 2021. Accessed 17 Jun 2021.

47. Wang M, Mu Z, Wang J, Hou S, Han L, Dong Y, et al. The identification of and relief from Fe3+ inhibition for both cellulose and cellulase in cellulose saccharification catalyzed by cellulases from Penicillium decumbens. Bioresour Technol. 2013;133:507-12. doi:10.1016/j.biortech.2013.01.172.

48. Risse M, Weber-Blaschke G, Richter K. Resource efficiency of multifunctional wood cascade chains using LCA and exergy analysis, exemplified by a case study for Germany. Resources, Conservation and Recycling. 2017;126:141-52. doi:10.1016/j.resconrec.2017.07.045.

49. Hu Z, Que Y, Gao Y, Yin Y, Zhao Y. Using Black Liquor from the Soda Pulping Process for Protein Production by Candida utilis. BioResources 2015. doi:10.15376/biores.10.3.3908-3921.

50. Shi S, Wang C, Fang S, Jia M, Li X. Removal performance and water quality analysis of paper machine white water in a full-scale wastewater treatment plant. Environ Technol. 2017;38:1443-51. doi:10.1080/09593330.2016.1231227.

51. Ekstrand E-M, Larsson M, Truong X-B, Cardell L, Borgström Y, Björn A, et al. Methane potentials of the Swedish pulp and paper industry - A screening of wastewater effluents. Appl Energy. 2013;112:50717. doi:10.1016/j.apenergy.2012.12.072.

52. Tobin T, Gustafson R, Bura R, Gough HL. Integration of wastewater treatment into process design of lignocellulosic biorefineries for improved economic viability. Biotechnol Biofuels. 2020;13:24. doi:10.1186/s13068-020-1657-7. 
53. Davis R, Grundl N, Tao L, Biddy MJ, Tan EC, Beckham GT, Humbird H. Process Design and Economics for the Conversion of Lignocellulosic Biomass to Hydrocarbon Fuels and Coproducts: 2018 Biochemical Design Case Update: Biochemical Deconstruction and Conversion of Biomass to Fuels and Products via Integrated Biorefinery Pathways. National Renewable Energy Laboratory NREL/TP5100-71949; 2018.

54. Zaky AS, Carter CE, Meng F, French CE. A Preliminary Life Cycle Analysis of Bioethanol Production Using Seawater in a Coastal Biorefinery Setting. Processes. 2021;9:1399. doi:10.3390/pr9081399.

55. STARK N, ESSIG D, BAKER S. Nutrient concentrations in Pinus ponderosa and Pseudotsuga menziesii xylem sap from acid and alkaline soils. Soil Sci. 1989;148:124-31. doi:10.1097/00010694-198908000-00006.

56. Saffell BJ, Meinzer FC, Woodruff DR, Shaw DC, Voelker SL, Lachenbruch B, Falk K. Seasonal carbohydrate dynamics and growth in Douglas-fir trees experiencing chronic, fungal-mediated reduction in functional leaf area. Tree Physiol. 2014;34:218-28. doi:10.1093/treephys/tpu002.

57. Woodruff DR, Meinzer FC. Water stress, shoot growth and storage of non-structural carbohydrates along a tree height gradient in a tall conifer. Plant, Cell \& Environment. 2011;34:1920-30. doi:10.1111/j.1365-3040.2011.02388.x.

58. Willför S, Sundberg A, Hemming J, Holmbom B. Polysaccharides in some industrially important softwood species. Wood Sci Technol. 2005;39:245-57. doi:10.1007/s00226-004-0280-2.

59. Krammer G, Lützen A, Seibel J. Cellobiose: Thieme Gruppe; 2021.

60. Willför S, Pranovich A, Tamminen T, Puls J, Laine C, Suurnäkki A, et al. Carbohydrate analysis of plant materials with uronic acid-containing polysaccharides-A comparison between different hydrolysis and subsequent chromatographic analytical techniques. Ind Crops Prod. 2009;29:571-80. doi:10.1016/j.indcrop.2008.11.003.

61. Fengel D, Wegener G. Wood: Chemistry, ultrastructure, reactions. Berlin: De Gruyter; 1984.

62. Pettersen RC. The Chemical Composition of Wood. In: Rowell R, editor. The Chemistry of Solid Wood. Washington, DC: American Chemical Society; 1984. p. 57-126. doi:10.1021/ba-1984-0207.ch002.

63. Valette N, Perrot T, Sormani R, Gelhaye E, Morel-Rouhier M. Antifungal activities of wood extractives. Fungal Biol Rev. 2017;31:113-23. doi:10.1016/j.fbr.2017.01.002.

64. Ximenes E, Kim Y, Mosier N, Dien B, Ladisch M. Inhibition of cellulases by phenols. Enzyme Microb Technol. 2010;46:170-6. doi:10.1016/j.enzmictec.2009.11.001.

65. Nagendran S, Hallen-Adams HE, Paper JM, Aslam N, Walton JD. Reduced genomic potential for secreted plant cell-wall-degrading enzymes in the ectomycorrhizal fungus Amanita bisporigera, based on the secretome of Trichoderma reesei. Fungal Genet Biol. 2009;46:427-35. doi:10.1016/j.fgb.2009.02.001.

66. Tejirian A, Xu F. Inhibition of enzymatic cellulolysis by phenolic compounds. Enzyme and Microbial Technology. 2011;48:239-47. doi:10.1016/j.enzmictec.2010.11.004.

67. Oleson KR, Schwartz DT. Extractives in Douglas-fir forestry residue and considerations for biofuel production. Phytochem Rev. 2016;15:985-1008. doi:10.1007/s11101-015-9444-y. 
68. Miranda I, Ferreira J, Cardoso S, Pereira H. Composition and antioxidant properties of extracts from Douglas fir bark. Holzforschung 2020. doi:10.1515/hf-2020-0097.

69. Cavka A, Alriksson B, Rose SH, van Zyl WH, Jönsson LJ. Production of cellulosic ethanol and enzyme from waste fiber sludge using SSF, recycling of hydrolytic enzymes and yeast, and recombinant cellulase-producing Aspergillus niger. J Ind Microbiol Biotechnol. 2014;41:1191-200. doi:10.1007/s10295-014-1457-9.

70. Scarcella ASdA, Pasin TM, Oliveira TB de, Lucas RC de, Ferreira-Nozawa MS, Freitas EN de, et al. Saccharification of different sugarcane bagasse varieties by enzymatic cocktails produced by Mycothermus thermophilus and Trichoderma reesei RP698 cultures in agro-industrial residues. Energy. 2021;226:120360. doi:10.1016/j.energy.2021.120360.

71. Szengyel Z, Zacchi G, Varga A, Réczey K. Cellulase Production of Trichoderma reesei Rut C 30 Using Steam-Pretreated Spruce. In: Finkelstein M, Davison BH, editors. Proceedings of the Twenty-First Symposium on Biotechnology for Fuels and Chemicals. New York: Springer Science+Business Media LLC; 2000. p. 679-691. doi:10.1007/978-1-4612-1392-5_52.

72. Wen Z, Liao W, Chen S. Production of cellulase by Trichoderma reesei from dairy manure. Bioresource Technology. 2005;96:491-9. doi:10.1016/j.biortech.2004.05.021.

73. Min BC, Bhayani BV, Jampana VS, Ramarao BV. Enhancement of the enzymatic hydrolysis of fines from recycled paper mill waste rejects. Bioresour. Bioprocess. 2015. doi:10.1186/s40643-015-0068-2.

74. dos Santos Castro L, Pedersoli WR, Antoniêto ACC, Steindorff AS, Silva-Rocha R, Martinez-Rossi NM, et al. Comparative metabolism of cellulose, sophorose and glucose in Trichoderma reesei using highthroughput genomic and proteomic analyses. Biotechnol Biofuels. 2014;7:41. doi:10.1186/17546834-7-41.

75. Bendig C, Weuster-Botz D. Reaction engineering analysis of cellulase production with Trichoderma reesei RUT-C30 with intermittent substrate supply. Bioprocess Biosyst Eng. 2013;36:893-900. doi:10.1007/s00449-012-0822-1.

76. Bischof R, Fourtis L, Limbeck A, Gamauf C, Seiboth B, Kubicek CP. Comparative analysis of the Trichoderma reesei transcriptome during growth on the cellulase inducing substrates wheat straw and lactose. Biotechnol Biofuels. 2013;6:127. doi:10.1186/1754-6834-6-127.

77. Ivanova C, Bååth JA, Seiboth B, Kubicek CP. Systems analysis of lactose metabolism in Trichoderma reesei identifies a lactose permease that is essential for cellulase induction. PLoS ONE. 2013;8:e62631. doi:10.1371/journal.pone.0062631.

78. Pirayre A, Duval L, Blugeon C, Firmo C, Perrin S, Jourdier E, et al. Glucose-lactose mixture feeds in industry-like conditions: a gene regulatory network analysis on the hyperproducing Trichoderma reesei strain Rut-C30. BMC Genomics. 2020;21:885. doi:10.1186/s12864-020-07281-8.

79. Liaw S-S, Haber Perez V, Zhou S, Rodriguez-Justo O, Garcia-Perez M. Py-GC/MS studies and principal component analysis to evaluate the impact of feedstock and temperature on the distribution of products during fast pyrolysis. Journal of Analytical and Applied Pyrolysis. 2014;109:140-51. doi:10.1016/j.jaap.2014.06.018. 
80. Zhou S, Wang Z, Liaw S-S, Li C-Z, Garcia-Perez M. Effect of sulfuric acid on the pyrolysis of Douglas fir and hybrid poplar wood: Py-GC/MS and TG studies. Journal of Analytical and Applied Pyrolysis. 2013;104:117-30. doi:10.1016/j.jaap.2013.08.013.

81. Berlin A, Balakshin M, Gilkes N, Kadla J, Maximenko V, Kubo S, Saddler J. Inhibition of cellulase, xylanase and beta-glucosidase activities by softwood lignin preparations. J Biotechnol. 2006;125:198-209. doi:10.1016/j.jbiotec.2006.02.021.

82. Ximenes E, Kim Y, Mosier N, Dien B, Ladisch M. Deactivation of cellulases by phenols. Enzyme Microb Technol. 2011;48:54-60. doi:10.1016/j.enzmictec.2010.09.006.

83. Qin L, Li W-C, Liu L, Zhu J-Q, Li X, Li B-Z, Yuan Y-J. Inhibition of lignin-derived phenolic compounds to cellulase. Biotechnol Biofuels. 2016;9:70. doi:10.1186/s13068-016-0485-2.

84. Li Y, Liu C, Bai F, Zhao X. Overproduction of cellulase by Trichoderma reesei RUT C30 through batchfeeding of synthesized low-cost sugar mixture. Bioresour Technol. 2016;216:503-10. doi:10.1016/j.biortech.2016.05.108.

85. Fukasawa Y, Osono T, Takeda H. Decomposition of Japanese beech wood by diverse fungi isolated from a cool temperate deciduous forest. Mycoscience. 2005;46:97-101. doi:10.1007/S10267-0040215-7.

86. Fukasawa $\mathrm{Y}$, Osono T, Takeda $\mathrm{H}$. Wood decomposing abilities of diverse lignicolous fungi on nondecayed and decayed beech wood. Mycologia. 2011;103:474-82. doi:10.3852/10-246.

87. Vermaas JV, Petridis L, Qi X, Schulz R, Lindner B, Smith JC. Mechanism of lignin inhibition of enzymatic biomass deconstruction. Biotechnol Biofuels. 2015;8:217. doi:10.1186/s13068-015-03798.

88. Rahikainen JL, Evans JD, Mikander S, Kalliola A, Puranen T, Tamminen T, et al. Cellulase-lignin interactions-the role of carbohydrate-binding module and $\mathrm{pH}$ in non-productive binding. Enzyme and Microbial Technology. 2013;53:315-21. doi:10.1016/j.enzmictec.2013.07.003.

89. Rahikainen J, Mikander S, Marjamaa K, Tamminen T, Lappas A, Viikari L, Kruus K. Inhibition of enzymatic hydrolysis by residual lignins from softwood-study of enzyme binding and inactivation on lignin-rich surface. Biotechnol Bioeng. 2011;108:2823-34. doi:10.1002/bit.23242.

90. Rahikainen JL, Moilanen U, Nurmi-Rantala S, Lappas A, Koivula A, Viikari L, Kruus K. Effect of temperature on lignin-derived inhibition studied with three structurally different cellobiohydrolases. Bioresource Technology. 2013;146:118-25. doi:10.1016/j.biortech.2013.07.069.

91. Boukari I, O'Donohue M, Rémond C, Chabbert B. Probing a family GH11 endo- $\beta$-1,4-xylanase inhibition mechanism by phenolic compounds: Role of functional phenolic groups. Journal of Molecular Catalysis B: Enzymatic. 2011;72:130-8. doi:10.1016/j.molcatb.2011.05.010.

92. Kaya F, Heitmann JA, Joyce TW. Influence of lignin and its degradation products on enzymatic hydrolysis of xylan. J Biotechnol. 2000;80:241-7. doi:10.1016/s0168-1656(00)00265-0.

93. Fritscher C, Messner R, Kubicek CP. Cellobiose metabolism and cellobiohydrolase I biosynthesis by Trichoderma reesei. Exp Mycol. 1990;14:405-15. doi:10.1016/0147-5975(90)90063-Y. 
94. Lo C-M, Zhang Q, Callow NV, Ju L-K. Cellulase production by continuous culture of Trichoderma reesei Rut C30 using acid hydrolysate prepared to retain more oligosaccharides for induction. Bioresource Technology. 2010;101:717-23. doi:10.1016/j.biortech.2009.08.056.

95. Najjarzadeh N, Matsakas L, Rova U, Christakopoulos P. How Carbon Source and Degree of Oligosaccharide Polymerization Affect Production of Cellulase-Degrading Enzymes by Fusarium oxysporum f. sp. lycopersici. Front Microbiol. 2021;12:652655. doi:10.3389/fmicb.2021.652655.

96. Chen Y, Wu C, Shen Y, Ma Y, Wei D, Wang W. N,N-dimethylformamide induces cellulase production in the filamentous fungus Trichoderma reesei. Biotechnol Biofuels. 2019;12:790. doi:10.1186/s13068019-1375-1.

97. Novy V, Schmid M, Eibinger M, Petrasek Z, Nidetzky B. The micromorphology of Trichoderma reesei analyzed in cultivations on lactose and solid lignocellulosic substrate, and its relationship with cellulase production. Biotechnol Biofuels. 2016;9:169. doi:10.1186/s13068-016-0584-0.

98. Zhang R, Barzee T. Clarifying Water and Wastewater with Fungal Treatment/Bioflocculation: International Patent; 18.01.2018.

99. Sharari M, Roohani M, Jahan Latibari A, Guillet A, Aurousseau M, Sharari A. Treatment of bagasse preparation effluent by Phanerochaete chrysosporium immobilized on polyurethane foam: Enzyme production versus pollution removal. Ind Crops Prod. 2013;46:226-33. doi:10.1016/j.indcrop.2013.02.001.

100. Dias AA, Bezerra RM, Pereira AN. Activity and elution profile of laccase during biological decolorization and dephenolization of olive mill wastewater. Bioresource Technology. 2004;92:7-13. doi:10.1016/j.biortech.2003.08.006.

101. Schwartz M, Perrot T, Aubert E, Dumarçay S, Favier F, Gérardin P, et al. Molecular recognition of wood polyphenols by phase II detoxification enzymes of the white rot Trametes versicolor. Sci Rep. 2018;8:8472. doi:10.1038/s41598-018-26601-3.

102. German Institute for Standardization (DIN). German Standard Methods for Examination of Water, Waste Water and Sludge; Determination of the Chemical Oxygen Demand (COD) in the Range over 15mg/l (H41);DIN 38409-41.

103. German Institute for Standardization (DIN). German standard methods for the examination of water, waste water and sludge;DIN 38406.

104. German Institute for Standardization (DIN). Water quality - Determination of calcium and magnesium - Atomic absorption spectrometric method;DIN EN ISO 7980.

105. German Institute for Standardization (DIN). Water quality - Determination of dissolved anions by liquid chromatography of ions;DIN EN ISO 10304-2.

106. Technical Associatioin of the Pulp and Paper Industry. Acid-Soluble Lignin in Wood and Pulp;TAPPI UM 250.

107. Technical Associatioin of the Pulp and Paper Industry. Acid-Insoluble Lignin in Wood and Pulp;TAPPI T 222. 
108. Technical Associatioin of the Pulp and Paper Industry. Carbohydrate composition of extractive-free wood and wood pulp by gas-liquid chromatography;TAPPI T 249.

\section{Figures}

\section{Figure 1}

Schematic diagram of the processes and respective products associated with the mechanical drying of wood chips intended for energy production and the resulting side-product, press water (PW), tested here for its suitability in enzyme production with T. reesei RUT-C30 and Bio-clarification with wood-degrading basidiomycete fungi.

\section{Figure 2}

Microscopic photographs of raw PW (a) and PW supernatant (b). c Volume-weighed particle size distribution of Douglas-fir PW supernatant by laser-diffraction. $\mathbf{d}$ Concentration of macro solids, micro solids, and dissolved substances in the PW. e Mass percentage of the main fractions of PW solids after acid hydrolysis, namely hydrolysate, acid soluble aromatics, and acid insoluble residues. $f$ Chromatogram of the Py-GC/MS of PW AIR with the predominant compound classes with exemplary formulas for 2methoxy-phenol, oleic acid, and campesterol

\section{Figure 3}

Spore concentration and phenotype of $T$. reesei RUT-C30 grown on various agars with combination of MA salts (MA), $0.2 \mathrm{~g} \mathrm{~L}^{-1}$ glucose (Glc), and press water (PW). Conidia were washed from the plates with equal amounts of water and quantified after 10 days, incubated at $25^{\circ} \mathrm{C}$ in constant light.

\section{Figure 4}

Endoglucanase and endoxylanase activities of T. reesei RUT-C30 cultivated in shaking flasks at $30{ }^{\circ} \mathrm{C}$ and $250 \mathrm{rpm}$. Avicel ( $1 \% \mathrm{w} / \mathrm{v})$ was used as a carbon source. a MA medium supplemented with different PW supernatant concentrations $(25,50,75,100 \%)$. b MA medium replacing salts $\left(\mathrm{KH}_{2} \mathrm{PO}_{4}, \mathrm{MgSO}_{4}, \mathrm{CaCl}_{2}\right)$, trace elements, and Avicel according to the raw PW concentration. MA 50x TE and 50x TE + 20x Fe are controls with increased trace element (TE) concentrations and iron, respectively. No trace elements were supplemented to PW concentrations starting at $55 \%$. c MA medium with $1 \%(\mathrm{w} / \mathrm{v})$ Avicel, $1 \%(\mathrm{w} / \mathrm{v})$ 
Avicel + sugars based on the concentration in $25 \%$ PW, and $25 \%$ PW supplemented with MA medium.

Error bars represent the standard deviation $(n=3)$. Significant differences $(p>0.05)$ relative to the control $(0$ $\% \mathrm{PW}$ ) are indicated by asterisk.

\section{Figure 5}

a Endoglucanase and endoxylanase activity of T. reesei RUT-C30 cultivated in MA medium with $1 \%(\mathrm{w} / \mathrm{v})$ Avicel, Douglas-fir wood powder, and PW solids. Shaking flasks cultivated at $30^{\circ} \mathrm{C}$ at $250 \mathrm{rpm}$.

Micrographs at $10 \mathrm{x}$ of 5 day old cultures with $\mathbf{b}$ Avicel, $\mathbf{c}$ ball-milled Douglas-fir wood, $\mathbf{d}$ ball-milled PW solids. Error bars represent the standard deviation $(n=3)$.

\section{Figure 6}

a Growth rate (by colony diameter) of several basidiomycetes on yeast malt extract agar supplemented with $25 \%$ and $75 \%$ (v/v) press water Douglas-fir with bark (PWB). Cultivation at $25^{\circ} \mathrm{C}$. Growth measured daily over a period of 2 weeks. Growth rate was calculated from the slope of the growth curve. Significance $(p<0.05)$ in relation to the control without PWB. b Turbidity $(600 \mathrm{~nm})$ of culture supernatants incubated in shaking flasks 4 days at $28^{\circ} \mathrm{C}$ and $100 \mathrm{rpm}$. Error bars represent the standard deviation of biological replicates $(n=3)$, thus the PW and PWB controls are displayed without error bars.

\section{Supplementary Files}

This is a list of supplementary files associated with this preprint. Click to download.

- Reppkeetal2022Additionalfile.docx 